ANADOLU, J. of AARI

ISSN: $1300-0225$ (Print)

E-ISSN: 2667-6087 (Online)

2021, 31 (1): 74-83

DOI: 10.18615 /anadolu.950076

\title{
Bazı Böğürtlen Çeşitlerinin Çiçek Tozu Performanslarının Farklı Inkübasyon Sicaklıklart ve Süreleri Boyunca Belirlenmesi
}

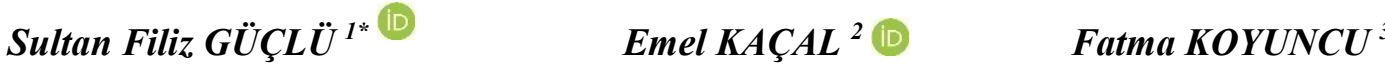 \\ ${ }^{1}$ Isparta Uygulamalı Bilimler Üniversitesi Atabey Meslek Yüksekokulu Bitkisel ve Hayvansal Üretim Bölümü, \\ Fidan Yetiştiriciliği Programı, Atabey-Isparta/ TURKEY \\ ${ }^{2}$ T.C. Tarım ve Orman Bakanlı̆̆ı, Meyvecilik Araştırma Enstitüsü Müdürlü̆̆̈̈, Ĕğirdir-Isparta/TURKEY \\ ${ }^{3}$ Isparta Uygulamalı Bilimler Üniversitesi, Ziraat Fakültesi, Bahçe Bitkileri Bölümü, Isparta/ TURKEY

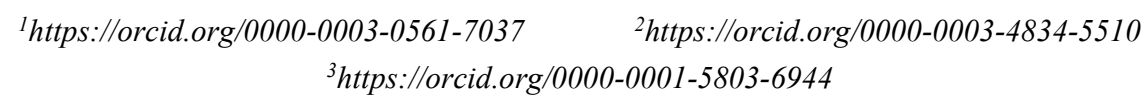 \\ *Corresponding author (Sorumlu yazar): sultanguclu@isparta.edu.tr \\ Received (Geliş tarihi): 07.01.2021 Accepted (Kabul tarihi): 05.03.2021
}

ÖZ: Bögürtlen, yüksek antioksidan miktarı ve kolay çoğaltılması nedeniyle önemli bir üzümsü meyvedir. Meyvecilikte etkili bir tozlanma için ilk şart canl, morfolojik homojenlik düzeyi yüksek, çimlenme yeteneğinde çiçek tozlarının bulunmasıdır. Bu çalışmada Navaho, Jumbo, Bursa I ve Bursa II bögürtlen çeşitlerine ait çiçek tozları kullanılmıştır. Çeşitlerin polen performanslarını belirleyebilmek amacıyla çiçek tozu üretim miktarlarl, çiçek tozu canlılık testleri, farklı sıcaklıklarda çiçek tozu çimlendirme ve çiçek tozu çim borusu uzunlukları belirlenmiştir. Bursa II çeşidi çiçek tozu üretim miktarl ve morfolojik homojenlik düzeyi bakımından en yüksek değerleri veren çeşit olmuştur. Çiçek tozu çimlenmesi ve tüp büyümesi için en uygun sıcaklığın $18{ }^{\circ} \mathrm{C}$ olduğu, sıcaklık yükseldikçe hem çimlenme oranının düştüğü hem de daha kısa çim borularının oluştuğu gözlenmiștir.

Anahtar kelimeler: Çiçek tozu çimlenmesi, TTC, küresel ısınma, çim borusu uzunluğu.

\section{Determination of Pollen Performance of Some Blackberry Varieties During Different Incubation Temperatures and Incubation Periods}

ABSTRACT: Blackberry is an important berry fruit due to its high antioxidant content and easy propagation. The first condition for effective pollination in fruit growing is the presence of vital pollen with high morphological homogeneity and germination ability. In fruit growing, which is one of the areas most affected by global climate changes, high temperatures can adversely affect pollen germination and pollen tube growth. Pollen belonging to Navaho, Jumbo, Bursa I and Bursa II blackberry varieties were used in the study. In order to determine the pollen performance of the cultivars, pollen production amounts, pollen viability tests, pollen germination at different temperatures and pollen tube growth measurement trials were conducted. Bursa II variety was the type that gave the highest values in terms of pollen production amount and morphological homogenity level.

Keywords: Pollen germination, TTC, global warming, pollen tube growth. 


\section{GİRIŞ}

Meyve üretimi, çiçek uyarımı ile başlayan, tozlanma, döllenme ve meyve gelişimi ile devam eden bir süreçtir (Kaçal ve Koyuncu, 2010). Başarılı bir tozlanma ve döllenme için ise ilk şart yeterli sayıda ve canlı çiçek tozlarının dişicik tepesi üzerine gelmesi, dişicik tepesine gelen çiçek tozlarının çimlenerek polen tüpünü meydana getirme yeteneğine sahip olması ve bu süreçte yumurtalığın canlı olmasıdır (Tosun ve Koyuncu, 2007; Güçlü ve ark., 2015). Çiçek tozlarının optimal çimlenme düzeyleri; bitki tür ve çeşidine, ortamın besin maddesi içeriğine, basınç, $\mathrm{pH}$ durumu ile ekolojilere göre değişebilmektedir (Eti, 1991; Voyiatzis ve Paraskevopoulou-Paroussi, 2002; Koyuncu, 2006). Bitkilerde erkek eşey hücresi olan çiçek tozlarının sağlıklı gelişmesi, canlılık ve çimlenme yeteneklerinin yüksek olması, döllenme olayının başarılı bir şekilde sonuçlanmasında büyük önem taşımaktadır (Engin ve Ünal, 2002; Özcan, 2020). Çiçek tozu kalitesi kriteri olarak da nitelenen bu özellikler yanında, çiçeklerde üretilen çiçek tozlarının kantitatif yönden de yüksek değerler taşıması istenir (Eti,1990; Sütyemez ve Eti, 1998). Tozlanma ve döllenme meyve tutma oranını etkileyen temel faktörlerdendir. Bu nedenle tür ve çeşitlerin çiçek tozu özellikleri ile diğer özelliklerinin bilinmesi yetiştiriciler ve sslahçılar için büyük önem taşımaktadır. Bir meyve türünde döllenme düzeyinin, dolayısıyla meyve tutumunun yüksek olmasında, çiçek tozu özelliklerinin (üretilen çiçektozu miktarı, çimlenme oranı vb.) önemli düzeyde etkisi bulunmaktadır

Böğürtlen, Rosales takımı, Rosineae alt takımı, Rosaceae familyası, Rosoideae alt familyasından Rubus cinsi içerisinde yer alan çalı formundaki bitkilerden oluşan, botanik olarak birleşik bir meyvedir. Bögürtlen çiçekleri çeşitlere bağlı olarak değişik uzunlukta iki yaşlı dalların ve bazı çeşitlerde de bir yaşlı dalların yan sürgünleri üzerindeki karışık tomurcukların sürmesiyle ortaya çıkar. Bögürtlenlerde çiçeklenme genellikle mayıs sonunda başlar, ağustos sonuna kadar devam eder (Ağaoğlu, 1986). Böğürtlen çeşitlerinin çoğu kendine verimlidir. Tozlanma genellikle arılarla olur, ancak rüzgâr da tozlanmada etkilidir. Ticari yetiştiricilikte 4 da alana 1-2 arı kovanı olacak şekilde bir düzenleme yapılmalıdır. Genetik yapıları bakımından poliploid karakterde olan bögürtlenlerde diğer tüm türlerde olduğu gibi cansız, morfolojik homojenlik düzeyi düşük, çimlenme yeteneği bakımından zayıf çiçek tozları tozlanma ve döllenmeyi, dolayısıyla meyve tutumunu olumsuz etkilemektedir (Türemiş ve Derin, 2000). Bu nedenle çiçek tozu ile ilgili yapılan in vitro çalışmalar böğürtlende de çeşit bazında önem kazanmaktadır. Son yıllarda üniversitelerin de bögürtlenle ilgili araştırmalara önem vermesinin de etkisiyle, 1slah çalışmaları, yetiştirme teknikleri ile ilgili çalışmalar ve adaptasyon çalışmaları hızla artmıştır (Demirsoy ve ark., 2006; Kafkas ve ark., 2006; Gündoğdu ve ark., 2016). Yabani formlarında çok sayıda çalışma yapılmasına karşın kültür çeşitlerinde bu sayının az olduğu dikkat çekmektedir. $\mathrm{Bu}$ nedenle çeşitlerin özellikle döllenme biyolojisine yönelik çalışmalar önem taşımaktadır (Eskimez ve ark., 2019).

Meyve yetiştiriciliği, çok yıllık bir tarımsal faaliyet olduğu için küresel iklim değişikliklerinden yüksek oranda etkilenmektedir. Küresel 1sınma, k1ş döneminde hava sıcaklığını arttırma potansiyeline sahiptir ve öngörülen bu sıcaklık değişimlerinin, çoğu meyve türü, asma ve sert kabuklu meyve yetiştiriciliğinin yaygın olduğu bölgelerde olumsuz etkilerinin olabileceği ifade edilmektedir (Şahin ve ark., 2015). Yüksek sicaklıkların tozlanma ve döllenmede önemli bir rolü olan arı faaliyetinin engellemesiyle meydana gelen olumsuz etkisi yanında, çiçek tozu canlılık, morfolojik homojenlik, çiçek tozu çimlenmesi ve çiçek tozu çim borusu uzunluğuna olumsuz etkisi nedeniyle de meyve yetiştiriciliğinde olumsuz etkileri söz konusudur. Polen ve polen tüp büyümesi, bitki türlerinin, aynı tür içindeki farklı çeşitlerin hatta genotiplerin stres koşullarında verdikleri tepkilerin anlaşılması için iyi bir belirteç olarak kullanılabilir (Çetinbaş-Genç ve ark., 2019). Bu çalışmada, yüksek antioksidan değeri ile son y1llarda öne çıkan böğürtlen meyve türüne ait dört çeşidin döllenme biyolojilerini araştırmak amacıyla çiçek tozu çimlendirme 
testleri yapılmış ve farklı sıcaklıkların çiçek tozu çimlenmesi ve çim borusu uzunluğuna etkisi araştırılmıştır.

\section{MATERYAL ve METOT}

Çalışmanın bitkisel materyalini, SDÜ Çiftçi Eğitim Merkezi (37.837124 enlem ve 30.538231 boylam) AR-GE parselinde bulunan, Navaho, Jumbo, Bursa I ve Bursa II böğürtlen çeşitleri oluşturmuştur. Laboratuvar çalışmaları, Isparta Uygulamalı Bilimler Üniversitesi Ziraat Fak. laboratuvarında yürütülmüştür.

Çiçek tozlarını elde etmek amacıyla sabah erken saatlerde, balon döneminde alınan çiçekler laboratuvara getirilmiş, anterler çıkarılarak 24 saat süresince, $25^{\circ} \mathrm{C}$ 'de bekletilmiştir. Çiçek tozu elde edildikten hemen sonra denemeler yapılmış, kalan çiçek tozları desikatör içinde $+4{ }^{\circ} \mathrm{C}$ 'de muhafaza altına alınmıştır.

Çeşitlere ait çiçek tozu üretim miktarları ve morfolojik homojenlik oranı "Hemasitometrik Lam" yöntemi ile belirlenmiştir (Eti, 1990). Bu amaçla, her ağaçtan henüz açmamış fakat açmak üzere olan 20 adet çiçek alınmıştır. Bu çiçekler 10'arlı iki gruba ayrılmış; her bir çiçeğin erkek organ başçıkları (anter) sayılarak, küçük şişeler içerisine erkek organ ipçikleri (filament) ayrılmış olarak konulmuştur. Her bir şişe içerisindeki 10'ar çiçeğe ait anterlerin kuruması ve patlamasını sağlamak amacıyla şişeler ağızları açık olarak güneş alan bir odanın kapalı bir penceresi önüne konulmuştur. Daha sonra her bir şişe içerisine 10 $\mathrm{ml}$ damıtık su konulmuştur. $\mathrm{Bu}$ suyun üzerine homojen çiçek tozu dağılımını sağlamak amacıyla yüzey gerilimini azaltacak bir madde eser miktarda damlatılmıştır. Bu amaçla tarımsal savaş ilaçları veya hormon püskürtmelerinde yayıcı-yapıştırıcı olarak kullanılan ve piyasada değişik adlarla satılan özel maddelerden yararlanılabileceği gibi, aynı görevi yapması sebebiyle çalışmada sıvı deterjan kullanılmıştır. Daha sonra hemasitometrik lam üzerinde sayım işlemi gerçekleştirilmiş ve morfolojik homojenlik oranı aşağıdaki formüle göre hesaplanmıştır.
$M H=\frac{\text { (Normal şekilli polen sayısı) }- \text { (Abortifpolen sayısı) }}{\text { Alandaki polen sayı1.s toplamı }} \times 100$

Norton (1966)'a göre hazırlanan tetrazolium çözeltisi (TTC) \%10'luk stok olarak hazırlanmıştır. Stok çözeltiden 1 kısım alınarak 9 kısım \%60'lık sakkaroz çözeltisi ile karıştırılıp TTC miktarı \%1 olarak ayarlanmıştır. Lamın üzerine 1 damla TTC çözeltisi damlatılmış çiçek tozları ekilmiş, üzerleri lamelle kapatılmıştır. Mikroskop altında 2 saat sonra yapilan sayımlarda, koyu kırmızi-turuncu boyanan çiçek tozları canlı, sarımsı pembe ya da renksiz olanlar cansız olarak kabul edilmiştir. İyotlu potasyum iyodür (IKI) testinde, çiçek tozları lamel üzerinde $1.0 \mathrm{~g}$ potasyum iyodür ve $0.5 \mathrm{~g}$ iyotun $100 \mathrm{ml}$ destile su içerisinde çözünmesiyle hazırlanan iyotlu potasyum iyodür (IKI) çözeltisi damlası üzerine ekilmiştir. Ekimden birkaç dakika sonra çiçek tozları renk değiştirmeye başlamıştır. Koyu kahverengi boyanan çiçek tozları canlı, açık kahverengi, sarımsı bej ya da boyanmayanlar cansız olarak kabul edilmiştir (Yıldız ve Kaplankıran,2014; Binici ve Dalkı1ıç, 2020).

Çiçek tozu çimlendirme denemeleri için "petride agar" yöntemi kullanılmıştır (Koyuncu ve ark., 2000; Güçlü ve Koyuncu, 2017). Yapılan ön denemeler sonucunda $\% 1$ agar $+\% 15$ sakkaroz +5 ppm borik asit içeren besi ortamı çimlendirme ortamı olarak belirlenmiştir. Çimlendirme ortamına ekilen çiçek tozları $6,12,24$ ve 48 saat boyunca $18,25,30$ ve $35{ }^{\circ} \mathrm{C}$ inkubasyon sicaklığında tutulmuşlardır. Daha önce yapılan ön denemeler sonucunda $18 \quad{ }^{\circ} \mathrm{C}$ kontrol sicaklığ 1 olarak belirlenmiştir. Çiçek tozu çim borusu uzunlukları, çiçek tozu ekiminden 24 saat sonra, Zeiss marka 1şık mikroskobu altında oküler mikrometre kullanarak 40 büyütme ile ölçülmüştür.

\section{İstatistiksel analizler}

In vitro çimlendirme denemelerinde, her çeşit için 4 petri kullanılmış ve her bir petri 4 bölgeye ayrılarak her bölgede toplam 400 adet çiçek tozu sayılmıştır. Çiçek tozlarının canlılık ve çimlendirme testleri ile üretim miktarını belirlemek üzere tesadüf parselleri deneme desenine göre dört tekerrürlü olarak yürütülen denemede verilerin 
değerlendirilmesinde SPSS 22.0 (SPSS Inc., USA) paket programı kullanılarak istatistiksel analiz yapılmıştır. Ortalamalar arasındaki fark LSD çoklu karşılaştırma testine göre $\mathrm{P}<0,05$ düzeyinde test edilmiştir (Bilgin ve Misırlı, 2017).

\section{BULGULAR}

Bursa I, Bursa II, Jumbo ve Navaho çeşitlerine ait çiçek tozu sayımları ve morfolojik homojenlik oranları Çizelge 1'de sunulmuştur. Bir çiçekte bulunan anter sayıs1 72,36 adet (Bursa II) ile 67,94 adet (Navaho) arasında değişmiştir. Bir anterdeki ortalama çiçek tozu sayısı bakımından Bursa II (209.66 adet) ve Bursa I (208.20 adet) çeşitleri ön plana çıkmıştır. Bir anterde en az çiçek tozu bulunduran çeşit Navaho (186.84 adet) olmuştur. Çeşitlerin ortalama çiçek tozu miktarları karşılaştırıldığında ise Bursa II 19301.2 adet ile en üst sırada yer alırken Navaho 11263.37 adet ile en az çiçek tozuna sahip çeşit olmuştur. Bursa II çeşidi morfolojik homojenlik düzeyi bakımından \%96,6 ile morfolojik homojenlik düzeyi en yüksek çeşit olmuştur. Bunu sırasıyla Bursa I $(\% 95,9)$, Jumbo $(\% 94,5)$ ve Navaho $(\% 94,2)$ çeşitleri izlemiştir.

Çiçek tozu canlılığını belirlemek için yapılan boyama testlerine ait sonuçlar Çizelge 2'de verilmiştir. Yapılan boyama testlerine göre çeşitlerin canlılıklarının ortalama değerleri karşılaştırıldığında
\%94,40 değeri ile Bursa II çeşidi en yüksek değere sahip olmuştur. Bunu Jumbo $(\% 89,85)$, Bursa I $(\% 81,00)$, ve son olarak Navaho $(\% 75,60)$ çeşitleri izlemiştir. Tüm çeşitler için boyama testleri ortalamaları karşılaştırıldığında IKI (İyotlu potasyum iyodür) testi $\% 87,42$ ile TTC (tetrazolium klorid) testine göre daha yüksek sonuç vermiştir.

Farklı sıcaklıkların çiçek tozu çimlenmesi üzerine etkilerinin incelenmesi için 4 farklı sicaklık koşulunda çiçek tozları çimlendirilmiştir. Daha önce yapılan ön denemelerle optimum çiçek tozu çimlenme sıcaklığ $18{ }^{\circ} \mathrm{C}$ olarak belirlenmiş ve bu sicaklık kontrol sicaklığı olarak ele alınmıştır. Farklı sıcaklıkların çiçek tozu çimlenme oranına etkisi Çizelge 3'de verilmiştir. Dört farklı sıcaklığın tüm çeşitler için ortalama değerleri karşılaştırıldığında çeşitlerin ortalama çimlenme oranlarına göre $18{ }^{\circ} \mathrm{C}$ 'de $\% 58,44$ ve $25{ }^{\circ} \mathrm{C}$ 'de ve $\% 57,47$ çimlenme oranı bulunmuştur. Sicaklık 30 ${ }^{\circ} \mathrm{C}$ 'ye çıktığında çiçek tozu çimlenme oranı tüm çeşitlerde düşmeye başlamış, ortalama çimlenme oranı \%37,52'ye düşmüştür. Yüksek sicaklığın olumsuz etkisiyle $35{ }^{\circ} \mathrm{C}$ 'de ortalama çimlenme oranı \%5,71 olmuştur. Farklı sıcaklıklarda çeşitler karşılaştırıldığında ise ortalama \%44,69 (Bursa II) ile \%32,25 (Navaho) arasında değiştiği görülmüştür.

Çizelge 1. Böğürtlen çeşitlerinde ortalama anter sayısı, bir anterdeki ortalama çiçek tozu sayısı, bir çiçekteki ortalama çiçek tozu sayısı ve morfolojik homojenlik oranları.

Table 1. Average number of anthers in blackberry varieties, average pollen number in an anther, average pollen number in a flower and morphological homogeneity ratios.

\begin{tabular}{|c|c|c|c|c|}
\hline $\begin{array}{l}\text { Çeşitler } \\
\text { Varieties }\end{array}$ & $\begin{array}{l}\text { Bir çiçekteki ortalama } \\
\text { anter sayısı (adet)* } \\
\text { Average number of } \\
\text { anthers (number) }\end{array}$ & $\begin{array}{l}\text { Bir anterdeki ortalama } \\
\text { çiçek tozu sayısı (adet)* } \\
\text { Average pollen number in } \\
\text { an anther (number) }\end{array}$ & $\begin{array}{l}\text { Bir çiçekteki ortalama } \\
\text { çiçek tozu sayısı (adet)* } \\
\text { Average pollen number in } \\
\text { a flower (number) }\end{array}$ & $\begin{array}{c}\text { Morfolojik homojenlik } \\
(\%) \\
\text { Morphological } \\
\text { homogeneity ratios }\end{array}$ \\
\hline Bursa I & $71,97 a$ & $208,20 \mathrm{a}$ & $17214,00 \mathrm{~b}$ & 95,9 \\
\hline Bursa II & $72,36 a$ & $209,66 a$ & $19301,21 \mathrm{a}$ & 96,6 \\
\hline Jumbo & $69,71 b$ & $204.91 \mathrm{a}$ & $14987,11 \mathrm{c}$ & 94,5 \\
\hline Navaho & $67,94 b$ & $186,84 b$ & $11263,37 d$ & 94,2 \\
\hline LSD Çeşit & 1,19 & 6,21 & 1,97 & \\
\hline CV (\%) & 3,2 & & & \\
\hline
\end{tabular}

*Aynı sütundaki farklı harfle gösterilen değerler arasındaki fark istatistik olarak önemlidir $(\mathrm{p}<0,05)$. ${ }^{*}$ The difference between values represented by different letters in the same column is statistically significant. 
Çizelge 2. Canlılık testlerinin çeşitlere göre çeşitlerin canlılık oranları (\%).

Table 2 . Viability rates of varieties according to viability tests $(\%)$.

\begin{tabular}{lccc}
\hline $\begin{array}{l}\text { Çeşitler } \\
\text { Varieties }\end{array}$ & TTC & IKI & $\begin{array}{l}\text { Ortalama } \\
\text { (Mean) }\end{array}$ \\
\hline Bursa I & 78,50 & 83,50 & $81,00 \mathrm{~b}^{\mathrm{x}}$ \\
Bursa II & 93,60 & 95,20 & $94,40 \mathrm{a}$ \\
Jumbo & 86,20 & 93,50 & $89,85 \mathrm{a}$ \\
Navaho & 73,70 & 77,50 & $75,60 \mathrm{c}$ \\
Ortalama (Mean) & $83,00 \mathrm{~b}^{\mathrm{y}}$ & $87,42 \mathrm{a}$ & \\
\hline
\end{tabular}

LSD Cesit/Varieties: 3,27

LSD Boya: 2,65

CV $(\%): 3,66$

${ }^{\mathrm{x}}$ Aynı sütunda farklı harflerle gösterilen değerler arasındaki fark istatistiki olarak önemlidir $(\mathrm{p}<0.05) .{ }^{\mathrm{y}}$ Aynı satırda farklı harflerle gösterilen değerler arasındaki fark istatistiki olarak önemlidir $(p<0,05)$. ${ }^{x}$ The difference between the values shown with different

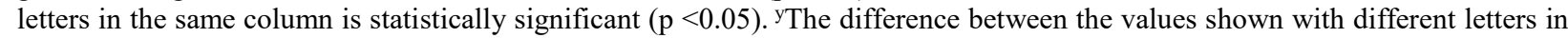
the same row is statistically significant $(\mathrm{p}<0.05)$.

Çizelge 3. Farklı sıcaklıkların çiçek tozu çimlenmesi üzerine etkisi.

Table 3. Effect of different temperatures on pollen germination.

\begin{tabular}{llllll}
\hline $\begin{array}{c}\text { Çeşitler } \\
\text { Varieties }\end{array}$ & $18^{0} \mathrm{C}$ & $25{ }^{\circ} \mathrm{C}$ & $30{ }^{\circ} \mathrm{C}$ & $35{ }^{0} \mathrm{C}$ & $\begin{array}{c}\text { Ortalama }^{\mathrm{x}} \\
(\mathrm{Mean})\end{array}$ \\
\hline Bursa I & 64,00 & 63,24 & 41,53 & 6,20 & $43,74 \mathrm{a}$ \\
Bursa II & 64,43 & 61,83 & 44,16 & 8,36 & $44,69 \mathrm{a}$ \\
Jumbo & 58,14 & 58,61 & 33,26 & 3,84 & $38,46 \mathrm{a}$ \\
Navaho & 47,21 & 46,20 & 31,16 & 4,46 & $32,25 \mathrm{~b}$ \\
Ortalama $^{y}$ & $58,44 \mathrm{a}$ & $57,47 \mathrm{a}$ & $37,52 \mathrm{~b}$ & $5,71 \mathrm{c}$ & \\
\hline
\end{tabular}

LSD Çeşit/Varieties: 5,59

LSD S1cakl1k/Temperature: 11,20

CV (\%): 5,46

${ }^{\mathrm{x} A y n}$ ı sütunda farklı harflerle gösterilen değerler arasındaki fark istatistiki olarak önemlidir $(\mathrm{p}<0,05)$. ${ }^{\mathrm{y} A y n}$ 1 satırda farklı harflerle gösterilen değerler arasındaki fark istatistiki olarak önemlidir $(\mathrm{p}<0,05)$. ${ }^{x}$ The difference between the values shown with different letters in the same column is statistically significant $(\mathrm{p}<0.05)$. ${ }^{\mathrm{y}}$ The difference between the values shown with different letters in the same row is statistically significant $(\mathrm{p}<0.05)$.

Çiçek tozu ekiminden 6 saat sonra $18{ }^{\circ} \mathrm{C}$ ve $25^{\circ} \mathrm{C}$ de hiçbir çeşitte çiçek tozu çimlenmesi başlamamıştır. Çiçek tozu ekiminden 12 saat sonra Bursa I ve Bursa II çeşitlerinde çimlenme olduğu görülmüştür $(\% 9,16-\% 8,16)$. Sicaklık artışının tüm çeşitlerde çimlenme süresini olumsuz etkilediği görülmektedir. Sıcaklık $35^{\circ} \mathrm{C}^{\prime}$ ye çıktığında ise inkubasyon süresine bağlı olmaksızın tüm çeşitlerde çiçek tozu çimlenme miktarının düştüğü görülmektedir. Tüm sıcaklıklarda bütün çeşitler kendi maximum değerine 48 saat sonra ulaşmışlardır (Şekil 1).
Farklı sıcaklıkların 24 saat sonra çiçek tozu çim borusu uzunluğuna etkisi Çizelge 4'de sunulmuştur. Ortalama çiçek tozu çim borusu uzunlukları karşılaş̧tırıldığında en uzun çiçek tozu çim boruları $25{ }^{\circ} \mathrm{C}$ 'de ölçülmüştür $116,68 \mu \mathrm{m}, 113,34 \mu \mathrm{m}$ ile bunu $30 \quad{ }^{0} \mathrm{C}$ izlemiştir. Sicaklığın $35{ }^{\circ} \mathrm{C}^{\prime}$ ye çıkmasıyla çim borusu uzunluğu azalmış ve 100,08 $\mu$ m'ye düşmüştür $(p<0,05)$. Farklı sicaklıklarda ortalama çim borusu uzunluğu bakımından çeşitler karşılaştırıldığında aralarındaki fark istatistik olarak önemli değildir. En uzun çim boruları Bursa II çeşidinde $(112,98 \mu \mathrm{m})$ ölçülmüştür. Bursa I

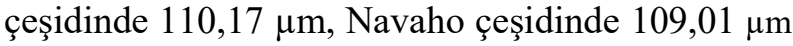
ve Jumbo çeşidinde 108,70 $\mu \mathrm{m}$ 'dir. 
S. F. GÜCLÜ, E. KACAL, F. KOYUNCU: BAZI BÖĞÜRTLEN CEESITLERININN ÇICCEK TOZU PERFORMANSLARININ FARKLI İNKÜBASYON SICAKLIKLARI VE SÜRELERİ BOYUNCA BELIRLENMESI

Çizelge 4. 24 saat sonra çeşitlerin farklı sıcaklıklardaki çim borusu uzunlukları $(\mu \mathrm{m})$.

Table 4. Pollen tube lengths at different temperatures after 24 hours later $(\mu \mathrm{m})$.

\begin{tabular}{lccccc}
\hline Çeşitler/ Varieties & $18^{0} \mathrm{C}$ & $25{ }^{\circ} \mathrm{C}$ & $30{ }^{\circ} \mathrm{C}$ & $35{ }^{0} \mathrm{C}$ & Ortalama/ Mean \\
\hline Bursa I & 113,17 & 117,15 & 112,16 & 98,23 & 110,17 \\
Bursa II & 109,89 & 119,23 & 116,51 & 106,30 & 112,98 \\
Jumbo & 109,81 & 114,24 & 113,31 & 97,45 & 108,70 \\
Navaho & 110,21 & 116,10 & 111,38 & 98,35 & 109,01 \\
Ortalama/ Mean $^{\mathrm{y}}$ & $110,77 \mathrm{a}$ & $116,68 \mathrm{a}$ & $113,34 \mathrm{a}$ & $100,08 \mathrm{c}$ & \\
\hline
\end{tabular}

LSD Sicaklık/ Temperature: 5,64

CV (\%): 4,98

${ }^{\mathrm{y}} \mathrm{Ayn}$ s satırda farklı harflerle gösterilen değerler arasındaki fark istatistiki olarak önemlidir $(\mathrm{p}<0.05) .{ }^{\mathrm{y}}$ The difference between the values shown with different letters in the same row is statistically significant $(\mathrm{p}<0.05)$.

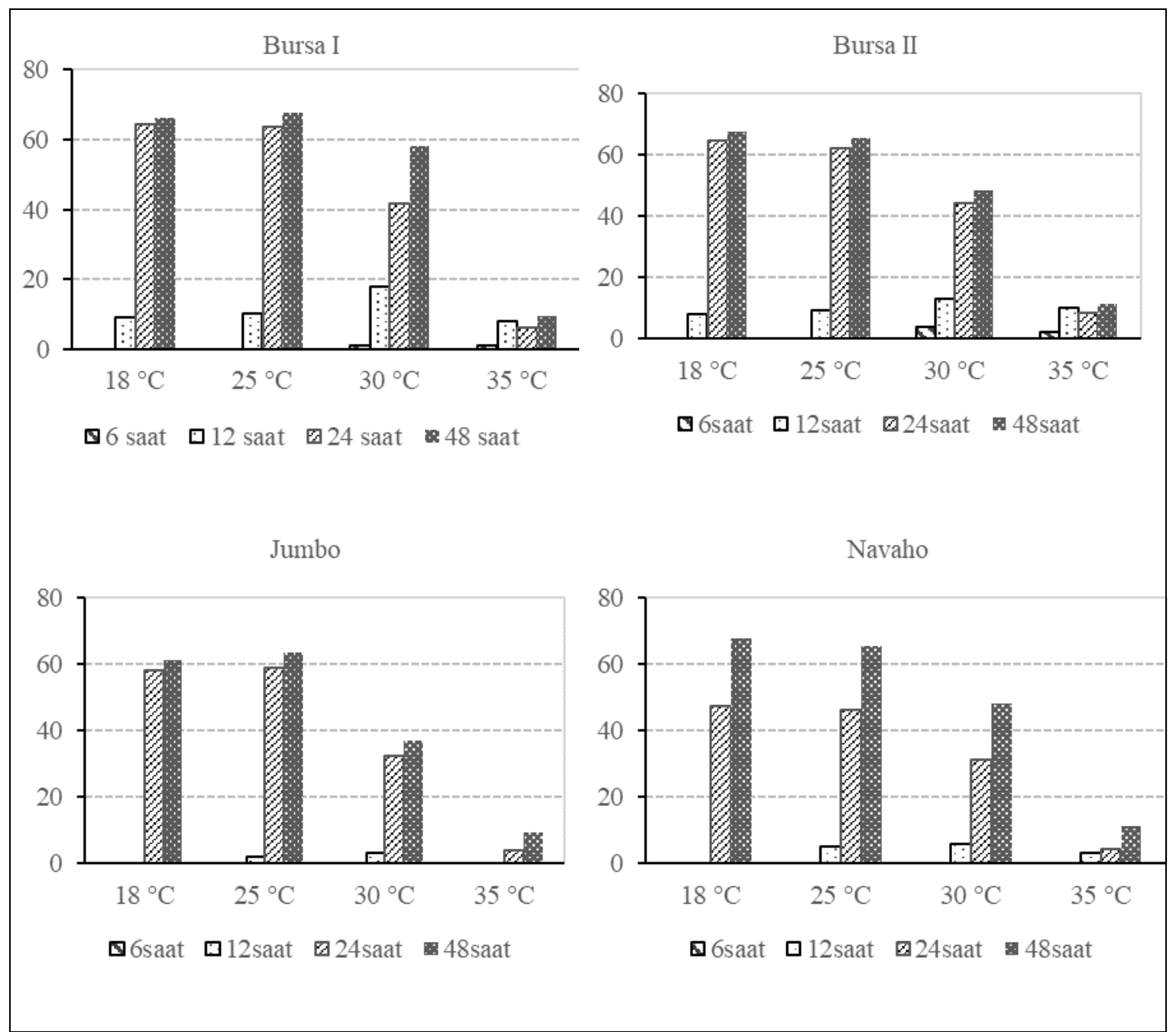

Şekil 1. Farklı sıcaklıklarda 4 farklı çeşidin 6, 12, 24 ve 48 saat inkubasyondan sonra çiçek tozu çimlenme yüzdeleri. Figure 1. Germination percentage of after $6,12,24,48$ hours incubation period of four different varieties. 


\section{TARTIŞMA}

Verimliliğin esas olduğu günümüz modern meyve yetiştiriciliği sistemlerinde, kullanılan çeşitlerin çiçek tozu üretim kapasiteleri, homojenlik durumları, canlılıkları ve çimlenme oranlarının bilinmesi, sürdürülebilir bir üretim için oldukça önemlidir. Çiçek tozlarının morfolojik olarak homojen olması, canlılık ve çimlenme yeteneklerinin artışını olumlu yönde etkilemektedir (Kazaz ve ark., 2020). Ayrıca morfolojik olarak homojen olmayan çiçek tozlarında yeterli bir tozlanma ve döllenme beklenmez. Morfolojik homojenlik tozlanma ve döllenme için mutlak gereklidir (Voyiatsiz ve ParaskevopoulouParoussi, 2002). Birçok meyve türü [kiraz (Tosun ve Koyuncu, 2007), kayısı (Abac1 ve Asma, 2014; Bilgin ve Misırl1, 2017), yenidünya (Karabıyık ve Eti, 2015)] çiçek tozu üretim miktarları bakımından incelenmiştir. Çalışma sonuçlarımıza paralel olarak bögürtlende yapılan başka bir çalışmada 1 çiçekteki anter sayıs1 Chester Thornless çeşidinde 79,0, Jumbo çeşidinde 70,5, Nessy çeşidinde 68,7, Oregon Thornles çeşidinde 55,5 bulunmuştur. Aynı çalışmada çeşitlerin morfolojik homojenlik oranları \%56,4 (Oregon Thornless) ile \%77,1 (Chester Thornless) arasında değişmiştir (Türemiş ve Derin, 2000). Çiçek tozu canlılığını belirlemede kullanılan boyama teknikleri; çiçek tozu enzim aktivitelerini, hücre bütünlüğünü ve çekirdeğin boyanabilirliğini tespit etmeyi amaçlamaktadır. $\mathrm{Bu}$ amaçla, asetokarmin, propione carmin, anilin mavisi (anilin blue), Alexander boyasi (Alexander's stain), IKI (iyotlu potasyum iyodür), FDA (flourescein diacetate), NBT(p-nitro blue tetrazolium), MTT (2,5-diphenyl tetrazolium bromide) ve TTC (2-2-5trifenil tetrazolium klorid) kullanilmaktadir (Vizintin ve Bohanec, 2004). Yapilan boyama testlerinde istatistiksel olarak bir fark olmasa da iyotlu potasyum iyodür testi tetrazolium klorid testine göre daha yüksek bir sonuç vermiştir. Benzer şekilde Asma (2008), kayısı polenlerinde yaptığ canlılık testinde iyotlu potasyum iyodürle yapılan boyama testinden tetrazolium klorid testine göre daha yükssek sonuçlar almıştır. Aynı şekilde Dorukoğlu ve Aslantaş (2013), farklı meyve türlerinin çiçek tozlarında canlılık testlerinde iyotlu potasyum iyodürün daha yüksek sonuçlar verdiğini bildirmişlerdir. Isparta'da doğal olarak yetişen bögürtlen tiplerinde polen performanslarının belirlenmesi için yapılan çalışmada polen canlılıkları TTC testi ile belirlenmiş, polen canlılık oranlarının \%79,88 ile \%83,22 arasında değiştiği bildirilmiştir (Güçlü ve ark., 2018). Çilek çeşitleri ile yapılan başka bir çalışmada çiçek tozu canlılığ için TTC boyama testi kullanmış ve çiçek tozu canlılık oranının \%82 (Allstar ve Elvira) ile \%86,5 (Chandler) arasında değiştiği bildirilmiştir. Ayrıca çeşitlerin morfolojik homojenlik oranının da oldukça yüksek olduğu tespit edilmiştir (Koyuncu, 2006). Çalışmamıza benzer şekilde çiçek tozu canlılık oranları, çiçek tozu çimlenme oranlarından yüksek çıkmıştır. Eti ve Stosser (1988) bu parametreler arasında doğrudan ve tutarlı bir ilişki olmadı ̆̆ını bildirmişlerdir. Son yıllarda araştırıcılar arasında çiçek tozu çimlenme testlerinin boyama testlerinden daha güvenilir olduğu, ancak pratik olması bakımından canlılık testlerinin seçildiği görüşü hakimdir (Impe ve ark., 2020).

Hükümetler arası İklim Değişikliği Paneli'nin 4. değerlendirme raporuna (Anonymous, 2014) temel teşkil eden yüksek emisyon senaryolu (A2) model simülasyonları, yüzyılın sonuna doğru Türkiye'de yıllık sıcaklıkların günümüze göre $3,1^{\circ} \mathrm{C}-5,2{ }^{\circ} \mathrm{C}$ arasında artacağını öngörmektedir (Uzunoğlu ve ark, 2015). Tarımın, günümüzde geçmişe nazaran çok kolay yapılması ve drenajdaki düzelmelere rağmen sıcaklıkların artması ve yıllık yağışların azalması, bitkilerde ürün kaybını ve su tüketimini artırmaktadır (Dockerty ve ark., 2006). Son yıllarda yapılan çalışmalarda yüksek sıcaklıkların ve sıcaklık dalgalanmalarının generatif organları vegetatif organlardan daha çok etkileyeceği bildirilmiştir. Dolayısıyla meyve tutumu da olumsuz olarak etkilenecektir (Hebbar ve ark., 2018). Çalışmamızda $18^{\circ} \mathrm{C}$ ve $25^{\circ} \mathrm{C}$, çiçek tozu çimlenmesi ve çim borusu uzaması için en uygun sıcaklıklar olarak belirlenmiş, yüksek sıcaklıkların çiçek tozu çimlenme oranı ve çim borusu uzunluğu üzerine olumsuz etki yaptığı görülmüştür. Çiçek tozu çimlenme oran $135^{\circ} \mathrm{C}$ ' de çok belirgin bir düşüş gösterirken, çiçek tozu çim borusu uzunluğunda meydana gelen azalma çok fazla değildir. Yani yüksek sıcaklıklarda çimlenen çiçek 
tozu sayısı az olsa da çiçek tozu çim borusu uzayabilmiştir. Buradan çiçek tozu çimlenmesinin çim borusu uzunluğuna göre yüksek sıcaklıklardan daha fazla etkilendiğini söyleyebiliriz. Çalışmamıza benzer şekilde Isparta'da doğal olarak yetişen bögürtlen tiplerinde $20^{\circ} \mathrm{C}$ çiçek tozu çimlenmesi ve çim borusu uzaması için en uygun sıcaklık olarak bulunmuştur (Güçlü ve ark., 2018). Red Lake ve Rosenthal çeşitlerinin polen performanslarının belirlendiği çalışmada $15^{\circ} \mathrm{C}$, 'Red Lake' çeşidi için en uygun çimlenme sicaklığ 1 olurken, $20{ }^{\circ} \mathrm{C}$, 'Rosenthal' çeşidi için optimum çimlenme sıcaklığı olarak bulunmuştur. İnkübasyon süresinin artmasıyla her iki çeşit içinde çiçek tozu çimlenme oranları artmıştır (Güçlü ve ark., 2019). Kirazda farklı sıcaklıkların çiçek tozu çim borusu uzaması üzerine yapılan başka bir çalışmada 20 ve $25^{\circ} \mathrm{C}$ en uygun çimlenme ve tüp büyümesi sıcaklığı olurken, bizim çalışmamızda olduğu gibi tüm çeşitlerde inkübasyon süresi arttıç̧a çimlenme oranı artmıştır (Koyuncu ve Güçlü, 2009). Badem çiçek tozlarında yapılan bir çalışmada düşük ve yüksek sıcaklıkların çiçek tozu çimlenmesi ve tüp büyümesi üzerine farklı oranlarda olumsuz etkisi olduğu bildirilmiştir. (Sorkheh ve ark., 2018). Çalışmamızdan elde edilen sonuçlara göre sıcaklık normalin üstünde değerlere çıtıkça çiçek tozu çimlenmesi azalmış, çim borusu uzunluğu bir süre artmış daha sonra ise onda da azalma meydana gelmiştir. Sonuçlarımıza paralel olarak çiçek tozu çimlenme oranları ve çim borusu büyümesi üzerine yüksek sıcaklıkların düşük sıcaklıklardan daha

\section{LITERATÜR LISTESİ}

Anonymous. 2014. Climate change. Assessment report of the intergovernmental panel on climate change. Geneva.

Abacı, Z.T ve B.M., Asma 2014. Melez kayısı genotiplerinde polen canlılık ve çimlenme durumları ile polen tüpü uzunluklarının araştırılması. Anadolu Tarım Bilimleri Dergisi 29(1): 12-19.

Ağaoğlu, S. 1986. Üzümsü Meyveler. Ankara Üniversitesi Ziraat Fakültesi. Yay. No:984. Ders kitabi: 290. Ankara.

Asma, B.M 2008. Determination of pollen viability, germination ratios and morphology of eight apricot genotypes. African Journal of Biotechnology 7(23): 4269-4273. fazla olumsuz etkisi olduğu bildirilmiștir (Kakani ve ark., 2002).

Çiçek tozu çimlenmesi ve çim borusu büyümesi morfolojik, fizyolojik, biyoteknolojik, ekolojik, biyokimyasal ve moleküler çalışmalar için çok nemli bir araştırma materyalidir. Çiçek tozu çimlenmesi ve çim borusu büyümesi üzerine etki eden faktörlerin araştırılması, pratik meyvecilikte kaliteli meyve tutumu ve meyvelerin döllenme biyolojileri çalışmalarına yardımcı olabilmektedir. $\mathrm{Bu}$ nedenle her tür hatta her çeşit için çiçek tozu çimlenme koşulları bilinmelidir.

\section{SONUÇ}

Çiçek tozu üretim miktarları, çiçek tozu morfolojik homojenlik oranları, çiçek tozu canlılık testleri, çiçek tozu çimlenme oranını içine alan "polen performansı" meyve yetiştiriciliğinde döllenme biyolojileri çalışmalarının temelidir. $\mathrm{Bu}$ nedenle tipler ve çeşitlerle ilgili yapılması gereken ilk çalışmalardandır. Çalışmamızda dört adet böğürtlen çeşidinin polen performansları belirlenmiştir. Bursa II çeşidi incelenen parametreler bakımından en iyi sonuçları veren çeşit olmuştur. Ayrıca son y1llarda üzerinde çokça tartışılan küresel ısınmanın meyvecilikte de olumsuz etkisi olabileceği, yüksek sıcaklıkların çiçek tozu performansını olumsuz etkileyebileceği ortaya konmuştur. Çalışmamızın, böğürtlende yapılacak 1slah ve adaptasyon çalışmalarına temel oluşturacağı pratik meyveciliğe de döllenme biyolojisi bakımından faydalı olacağı kanisindayız.

Bilgin, N.A. ve A. Mısırlı. 2017. Bazı kayısı çeşitlerinin çiçek tozu ve döllenme performanslarının belirlenmesi. Yüzüncü Y1l Üniversitesi Tarım Bilimleri Dergisi 27(2): 220-227.

Binici, S., ve G. G. Dalkılıç. 2020. Aydın ekolojisinde yetiștirilen bazı erik çeșitlerinde çiçek tozu kalite ve kantitesinin belirlenmesi. Adnan Menderes Üniversitesi Ziraat Fakültesi Dergisi 17(2): 263-270.

Çetinbaş-Genç, A., G. Cai,, , F. Vardar, and M. Ünal 2019. Differential effects of low and high temperature stress on pollen germination and tube length of hazelnut (Corylus avellana L.) genotypes. Scientia Horticulturae 255: 61-69.

Demirsoy, L., H. Demirsoy, Ş. Bilgener, A. Öztürk, B. Ersoy, G. Çelikel ve G. Balcı. 2006. Samsunda yapılan 
böğürtlen çeşit adaptasyon çalışmaları. II. Ulusal Üzümsü Meyveler Sempozyumu. Tokat. s 237-244.

Dockerty, T., A. Lovett, K. Appleton, A. Bone, and G. Sünnenberg. 2006. Developing scenarios and visualisations to 1llustrate potential policy and climatic influences on future agricultural landscapes agriculture. Ecosystems and Environment 114(1):103120.

Dorukoğlu, E. ve R Aslantaş 2013. Erzurum şartlarında yetiştirilen bazı meyve tür/çeşitlerinin polen kalitesi ve kantitesinin belirlenmesi. Atatürk Üniv. Ziraat Fak. Derg. 44(2): 111-119.

Engin, H. ve A. Ünal. 2002. Bornova şartlarında yetiştirilen kiraz çeşitlerinin çiçeklenme zamanları ve çiçeklenme dönemindeki sıcaklıkların çiçeklenme üzerine etkileri. Ege Üniversitesi Ziraat Fakültesi Dergisi 39(3):9-16.

Eskimez, I., M. Polat, N. Korkmaz ve K. Mertoğlu. 2019. Investigation of some blackberry cultivars in terms of phenological, yield and fruit characteristics. International Journal of Agriculture Forestry and Life Sciences 3(2): 233- 238.

Eti, S.1990. Çiçek tozu miktarını belirlemede kullanılan pratik bir yöntem. Canlılık ve çimlenme yeteneklerinin belirlenmesi. Çukurova Üniversitesi Ziraat Fakültesi Dergisi 6(1): 69-88, Adana.

Eti, S., 1991. Bazı meyve tür ve çeşitlerinde değişik in vitro testler yardımıyla çiçek tozu canlılık ve çimlenme yeteneklerinin belirlenmesi. Çukurova Üniversitesi Ziraat Fakültesi Dergisi 6(1): 69-81.

Eti, S., and R. Stösser. 1988. Fruchtbarkeit der Mandarinensorte "Clementine" (Citrus reticulata Blanco) I. Polenqualitat und Pollenschlauchwachstum. Gartenbauwiss 53 (4): 160-166.

Güçlü, S.F., Z. Öncü ve F. Koyuncu. 2015. Bazı sert çekirdekli meyve türlerinde çiçek tozu çimlenmesi ve çim borusu uzunluğunun çoklu regresyon yöntemi ile modellenmesi. Süleyman Demirel Üniversitesi Fen Bilimleri Enstitüsü Dergisi 19(3): 92-97.

Güçlü, S.F., and F. Koyuncu. 2017. An in vitro study of commercial fungicide effects on pollen germination in apple. Scientific Papers-Series B. Horticulture (61): 87-90.

Güçlü, S. F., A.G. Sarıkaya, and F. Koyuncu. 2018. Pollen performances of naturally grown blackberries in Isparta-Turkey. Scientific Papers Series B. Horticulture 62: 141-146.

Güçlü, S.F., M. Polat, and V. Okatan. 2019. Pollen performance of 'Red Lake' and 'Rosenthal' currant (Ribes rubrum) cultivars. Ege Üniversitesi Ziraat Fakültesi Dergisi 56(3): 313-317.

Gündoğdu, M., T. Kan, and I. Canan. 2016. Bioactive and antioxidant characteristics of blackberry cultivars from East Anatolia. Turkish Journal of Agriculture and Forestry 40(3): 344-351.
Hebbar, K.B., H.M. Rose, A.R. Nair, S. Kannan, V. Niral, M. Arivalagan, and P.V. Prasad. 2018. Differences in in vitro pollen germination and pollen tube growth of coconut (Cocos nucifera L.) cultivars in response to high temperature stress. Environmental and Experimental Botany 153: 35-44.

Impe, D., J.Reitz, C. Köpnick, H. Rolletschek, A. Börner, A.Senula, and M. Nagel. 2020. Assessment of pollen viability for wheat. Frontiers in Plant Science 10: 1588.

Kaçal, E. ve F. Koyuncu. 2010. Jerseymac ve Jonagold elma çeşitlerinde çiçek tomurcuğu farklılaşma sürecinin belirlenmesi. Ege Üniversitesi Ziraat Fakültesi Dergisi 47(3): 303-307.

Kafkas, E., M. Koşar, N. Türemiş ve K.H.C. Başer. 2006. Analysis of sugars, organic acids and vitamin C contents of blackberry genotypes from Turkey. Food Chemistry 97(4): 732-73.

Kakani, V.G., , P.V. Prasad, P.Q Craufurd, and T.R, Wheeler. 2002. Response of in vitro pollen germination and pollen tube growth of groundnut (Arachis hypogaea L.) genotypes to temperature. Plant Cell Environ. 25 (12): 1651-1661.

Karabıyık, Ş. ve S. Eti. 2015. Farklı yenidünya çeşitlerinin değişik çiçeklenme dönemlerinde çiçek tozu canlılık ve çimlenme düzeyleri ile üretim miktarlarının belirlenmesi. Meyve Bilimi 2(1): 42-48.

Kazaz, S., E. Doğan, T. Kılıç, E.G.E. Şahin, H. Dursun ve G.S. Tuna. 2020. Polen kaynağı olarak kokulu gül genotipleri ile yapılan tozlama tohum oluşumunu etkiler mi? Ege Üniversitesi Ziraat Fakültesi Dergisi 57(3): 393-399.

Koyuncu, F. 2006. Response of in vitro pollen germination and pollen tube growth of strawberry cultivars to temperature. European Journal of Horticultural Science 71(3): 125.

Koyuncu, F., H. Yılmaz ve M.A. Aşkın. 2000. Bazı çilek çeşitlerinde çiçek tozu üretim miktarları ve çimlenme oranının belirlenmesi üzerinde bir araştırma. Turkish Journal of Agriculture and Forestry 24:699-703.

Koyuncu, F. and S.F. Güçlü. 2009. Effect of temperature on in vitro pollen germination and tube growth in sweet cherries. American-Eurasian Journal of Agricultural and Environmental Science 6(5): 520-525.

Norton, J. D., 1966. Testing of Plum Polen Viability With Tetrazolium Salts. Proceedings of the American Society for Horticultural Science 89: 354-356.

Özcan, A. 2020. Effect of Low-temperature storage on sweet cherry (Prunus avium L.) pollen quality. HortScience 55(2): 258-260.

Sorkheh, K., R., Azimkhani, N. Mehri, M.H. Chaleshtori, , J. Halasz, S. Ercisli, and G.C. Koubouri. 2018. Interactive effects of temperature and genotype on almond (Prunus dulcis L.) pollen germination and tube length. Sci Hortic. 227: 162-16. 
S. F. GÜCLÜ, E. KACAL, F. KOYUNCU: BAZI BÖĞÜRTLEN CESSITLERİNIN CCICCEK TOZU PERFORMANSLARININ FARKLI İNKÜBASYON SICAKLIKLARI VE SÜRELERİ BOYUNCA BELIRLENMESİ

Sütyemez, M. ve S. Eti. 1998. Pozantı ekolojik koşullarında yetiştirilen bazı kiraz çeşitlerinin döllenme biyolojileri üzerine araştırmalar. Turkish Journal of Agriculture and Forestry 23:265.

Şahin, M., E. Topal, N. Özsoy ve E. Altunoğlu. 2015. İklim değişikliğinin meyvecilik ve arıcılık üzerine etkileri. Anadolu Doğa Bilimleri Dergisi 6:147-154.

Tosun, F. and F. Koyuncu. 2007. Investigations of suitable pollinator for 0900 Ziraat sweet cherry cv.: pollen performance tests, germination tests, germination procedures, in vitro and in vivo pollinations. Horticultural Science 34(2): 47-53.

Türemiş, N. F. ve K. Derin. 2000. Bazı böğürtlen (Rubus fruticosus L.) çeşitlerinin çiçek tozu canlılık düzeyleri ve üretim miktarları ile uygun çiçek tozu çimlendirme ortamının saptanması. Turkish Journal of Agriculture and Forestry 24(5): 637-642.
Uzunoğlu, F., S. Bayazit ve K. Mavi. 2015. Küresel iklim değişikliğinin süs bitkileri yetiştiriciliğine etkisi. Mustafa Kemal Üniversitesi Ziraat Fakültesi Dergisi 20(2): 66-75.

Vizintin, L. and B. Bohonec. 2004. In vitro manipulation of cucumber (Cucumis sativus ) polen and microspores: izolation procedures, viability tests, germination maturation. Acta Biologica Cracoviensia Series Botanica 46:177-183.

Voyiatzis, D. G., and G. Paraskevopoulou- Paroussi. 2002. Factors affecting the quality and in vitro germination capacity of strawberry pollen. Horticulture Science and Biotechnology 77(2): 200-203.

Yıldız, E. ve M. Kaplankıran. 2014. Trabzon hurmas1 genotiplerinin çiçek tozu canlllık ve çimlenme oranları. Ege Üniversitesi Ziraat Fakültesi Dergisi 51(2): 117-123. 